\title{
The issue of immigrants in Italy: a rational model of immigration management by Italian municipalities
}

\author{
Marco Baudino
}

Correspondence:

marco.baudino@edle-phd.eu; marco.baudino1@gmail.com

Department of Economics, Erasmus University Rotterdam,

Burgemeester Oudlaan 50, 3062 PA Rotterdam, The Netherlands

\begin{abstract}
This paper aims to analyze the increasing issue of overcongestion affecting the immigra tion hosting facilities of many Italian municipalities, as well as the heterogeneity in immigration regulatory behavior emerging among the latter. Since 2014, the immigration rate in Italy has tripled and the redistribution process of immigrants among municipalities has increased in a sustained manner. Municipalities receive financial subsidies from the central government for hosting immigrants; at the same time, many of them have been experiencing a series of rigidities in the form of complaints by both firms and local residents when having to modify their desired rate of immigrant arrivals. I introduce an intertemporal dynamic framework where a municipal authority rationally maximizes its utility from allowing immigrants to relocate to its jurisdiction, while considering the disutility cost of rigidities and the negative repercussions of having a congestion level of its hosting facilities different from the optimal one. From the model, two major findings emerge. Firstly, the optimal congestion level for a municipality always corresponds to a situation of overcongestion. Secondly, even though the level of rigidities does not affect the steady-state level, it does affect the process of convergence towards it, resulting in either monotonic or oscillating paths of convergence.
\end{abstract}

Keywords: Immigration, Dynamic optimization

JEL classification: R23, C61, P25

\section{Introduction}

The immigration phenomenon in Europe has started to increase dramatically since the beginning of the new century. Important and recent events such as the civil wars in Lybia, Syria, and Iraq have disrupted the geopolitical equilibrium in Northern Africa and the Middle East, provoking thousands of casualties, countless displaced people, and a grave power vacuum; the resulting state of anarchy facilitated a remarkable increase in the immigration rate not only from these regions but also from Sub-Saharan African countries and other countries such as Afghanistan, Bangladesh, and Pakistan. Since 2014, the European Union (E.U.) has witnessed a dramatic increase in the arrivals of immigrants asking for political asylum. Due to their geographical location, Italy and Greece have been the two E.U. member states which have been receiving the highest number of immigrants. After the agreement signed between the E.U. and Turkey in March 2016, nowadays, almost all of the immigration flows in Europe arrive from Libya and other parts of Northern Africa, so that Italy surpassed Greece as Europe's major point of entry (The

(C) The Author(s). 2017 Open Access This article is distributed under the terms of the Creative Commons Attribution 4.0 International License (http://creativecommons.org/licenses/by/4.0/), which permits unrestricted use, distribution, and reproduction in any medium, provided you give appropriate credit to the original author(s) and the source, provide a link to the Creative Commons license, and indicate if changes were made. 
New York Times 2016). In particular, the number of immigrants entering the Italian territory switched from 42,925 in 2013 to 153,842 in 2015 and 181,436 in 2016 (Ministry of Interior 2016; UNHCR 2016). To face this emergency, the European Union has increased funding for border patrol operations in the Mediterranean and elaborated plans to combat the smuggling of immigrants (the "Operation Sophia"). Despite all the countermeasures adopted by the E.U. to cope effectively with immigration, the burden of asylum seekers is not shared in an equal way among member states, with Italy remaining the member country bearing the greatest burden; first of all, a proper reform of the Dublin treaty (which requires the countries in which the first registration of immigrants takes place to host them) has not yet been accomplished (BBC 2016); moreover, the plan of quotas to redistribute asylum seekers between member states approved by the European Commission in 2015 has met scarce implementation, since many E.U. countries (for instance, Poland, Hungary, and Slovakia) have strongly opposed the plan and refused to receive their quotas of immigrants (Daily Express 2016). As a result, in the last 2 years, Italy has been accepting and redistributing on its territory almost the entirety of the immigration flows, and this has created financial and logistic issues to the Italian government, due to the limited hosting capacity of the country together with inadequate financial support from the E.U. (The Daily Telegraph 2015). With reference to the provenience of immigrants entering Italy, in 2015, 74\% of them was from Sub-Saharan Africa, 7\% from Bangladesh, 6\% from Pakistan, $1 \%$ from Syria, and $12 \%$ from other countries. Moreover, $85 \%$ of all immigrants were male against 15\% of women. All these trends remained virtually unchanged in 2016 (Ministry of Interior 2016).

The Italian management system of immigrants is rather articulated. In synthesis, upon arrival, immigrants are sent to the Centri di Prima Accoglienza, which are hubs where they are gathered and subject to a first general control. Those who do not meet the requirements of asylum seekers are expelled, the others are redistributed to the so-called centri SPRAR (Sistema di Protezione per Richiedenti Asilo e Rifugiati), namely municipal hosting facilities directly managed by the municipal authorities or hosting facilities belonging to specific associations under the direct supervision of the municipality. All the immigrants who get relocated to the hosting municipal facilities are subsequently subject to a second control for regularity by the municipal officers of the Ministry of Interior; because of this, a recurrent number of immigrants in every municipality gets repatriated due to the failure in meeting the necessary requirements to be granted the status of refugees (TGcom24 2016).

Being previously the redistribution of immigrants to SPRAR facilities on a pure voluntary basis, in December 2016, to cope with an increasing and uninterrupted flow of immigrants, the government has obliged each Italian municipality to host a minimum of three immigrants every 1,000 inhabitants, providing financial subsidies for every immigrant hosted (Il Giornale 2016a). Specifically, the central government provides an average of 35 euros per day for each immigrant; this amount was computed through an evaluation of the operating hosting costs incurred daily by municipalities, amounting on average to 27 euros per immigrant; thus, the resulting average profit for municipalities amounts to 8 euros per day per immigrant hosted (Il Giornale 2014). This program enabled by the central government has been targeted to incentivize municipalities to host additional immigrants, in order to better cope with the immigration emergency. As for the location of municipalities hosting more immigrants, no precise geographic 
pattern emerges; indeed, among the Italian municipalities which have been hosting the highest number of immigrants in the last 2 years, it is possible to find Rome, Catania, Milano, and Bari, which represent cities located in regions far from each other (Istat 2016).

Table 1 provides descriptive statistics at regional level for the number of immigrants hosted, expelled, and who arrived in Italy in the years 2015 and 2016.

The immigration policy of Italian municipalities has led to different reactions in the public opinion, especially when differentiating between citizens and firms. According to recent opinion polls, the majority of Italian citizens is against the current hosting policy of municipalities; a detailed survey conducted in 2016 by an Italian research institute over a sample of 800 random people belonging to 30 different municipalities contributed to confirm this trend. Specifically, people interviewed were asked for their opinion on the consistent arrivals of immigrants and the action they would like to undertake; $27 \%$ of the respondents was in favor of expelling all the immigrants, $50 \%$ of accepting only a restricted number of them, and 19\% of accepting them all and 4\% did not know (Eumetra 2016). Conversely, two different surveys conducted in 2015 and 2016 by the Italian Chamber of Commerce for a sample of over 100,000 firms through their respective entrepreneurial bodies, provided a remarkably opposite outcome (Excelsior 2015; Excelsior 2016). Indeed, these surveys highlighted how the growing need for unskilled labor over the past few years has been representing a significant and constant trend in the Italian industrial reality, affecting almost the whole totality of the sectors; because of this, on average, the demand for immigrant workers ${ }^{1}$ by Italian firms has been registering a positive and constant increase of around 5\% since 2013 (further increasing of a few percentage points in the period 2015-2016) ${ }^{2,3}$. As a consequence, in order to better deal with this issue, many Italian enterprises have entered into direct negotiations with their respective municipalities with the aim of obtaining a positive and predetermined rate of immigrant arrivals to offset their growing need of unskilled labor. Nevertheless, the bureaucratic rules that remain in Italy for the regularization process of immigrants and the recruitment procedures involving the latter by firms (see, e.g., the 189/2002 law) remain considerable, especially when compared to other European countries (Finotelli 2011). As a result, the period of stay of immigrants in the municipal hosting facilities and the recruitment procedures by firms get longer. ${ }^{4}$ In light of this, and of other factors such as the high population density of Italy, the particular urban structure of Italian municipalities, and the limited hosting capacity of many municipal facilities, an increasing number of municipalities is currently experiencing situations of overcongestion (La Repubblica 2016; Il Messaggero 2016); the pressure exercised by firms and the financial subsidies provided by the central government for hosting additional immigrants have additionally contributed to exacerbate this condition, also due to the fact that many Italian municipalities facing financial issues have exploited this opportunity to gain additional revenues (Il Giornale 2016b).

At the same time, contrary to the mainstream positive attitude of firms towards immigration, local residents in some municipalities have been protesting actively against the uninterrupted arrivals of immigrants. Conversely, in other places, the same level of protests by local residents has been much more contained, whereas in some other municipalities, the attitude of firms towards immigrants has been less accommodating, resulting hence in different scenarios (TGcom24 2017). Specifically, with reference to 
Table 1 Immigration trends 2015-2016 in Italy (Regional level)

\begin{tabular}{|c|c|c|c|c|}
\hline Region & Year & $\begin{array}{l}\text { Immigrants hosted in } \\
\text { SPRAR facilities }\end{array}$ & Arrivals $^{a}$ & Expulsions $^{b}$ \\
\hline Lombardia & $\begin{array}{l}2015 \\
2016\end{array}$ & $\begin{array}{l}13,894 \\
23,163\end{array}$ & $\begin{array}{l}19,999 \\
23,587\end{array}$ & $\begin{array}{l}8588 \\
14,318\end{array}$ \\
\hline Lazio & $\begin{array}{l}2015 \\
2016\end{array}$ & $\begin{array}{l}12,670 \\
14,780\end{array}$ & $\begin{array}{l}11,077 \\
13,063\end{array}$ & $\begin{array}{l}9390 \\
10,953\end{array}$ \\
\hline Veneto & $\begin{array}{l}2015 \\
2016\end{array}$ & $\begin{array}{l}8242 \\
13,630\end{array}$ & $\begin{array}{l}13,538 \\
15,966\end{array}$ & $\begin{array}{l}6397 \\
10,578\end{array}$ \\
\hline Piemonte & $\begin{array}{l}2015 \\
2016\end{array}$ & $\begin{array}{l}7941 \\
14,069\end{array}$ & $\begin{array}{l}11,692 \\
13,789\end{array}$ & $\begin{array}{l}4324 \\
7661\end{array}$ \\
\hline Campania & $\begin{array}{l}2015 \\
2016\end{array}$ & $\begin{array}{l}8129 \\
14,501\end{array}$ & $\begin{array}{l}12,154 \\
14,333\end{array}$ & $\begin{array}{l}4463 \\
7961\end{array}$ \\
\hline Sicilia & $\begin{array}{l}2015 \\
2016\end{array}$ & $\begin{array}{l}7905 \\
13,634\end{array}$ & $\begin{array}{l}13,077 \\
15,422\end{array}$ & $\begin{array}{l}5620 \\
9693\end{array}$ \\
\hline Toscana & $\begin{array}{l}2015 \\
2016\end{array}$ & $\begin{array}{l}7203 \\
12,444\end{array}$ & $\begin{array}{l}10,307 \\
12,156\end{array}$ & $\begin{array}{l}4003 \\
6915\end{array}$ \\
\hline Emilia-Romagna & $\begin{array}{l}2015 \\
2016\end{array}$ & $\begin{array}{l}6528 \\
12,880\end{array}$ & $\begin{array}{l}10,615 \\
12,519\end{array}$ & $\begin{array}{l}3126 \\
6167\end{array}$ \\
\hline Puglia & $\begin{array}{l}2015 \\
2016\end{array}$ & $\begin{array}{l}6424 \\
11,788\end{array}$ & $\begin{array}{l}11,384 \\
13,426\end{array}$ & $\begin{array}{l}4394 \\
8062\end{array}$ \\
\hline Calabria & $\begin{array}{l}2015 \\
2016\end{array}$ & $\begin{array}{l}4068 \\
7182\end{array}$ & $\begin{array}{l}6154 \\
7257\end{array}$ & $\begin{array}{l}2347 \\
4143\end{array}$ \\
\hline Liguria & $\begin{array}{l}2015 \\
2016\end{array}$ & $\begin{array}{l}3659 \\
5658\end{array}$ & $\begin{array}{l}4000 \\
4717\end{array}$ & $\begin{array}{l}1758 \\
2718\end{array}$ \\
\hline Sardegna & $\begin{array}{l}2015 \\
2016\end{array}$ & $\begin{array}{l}3247 \\
5470\end{array}$ & $\begin{array}{l}4308 \\
5080\end{array}$ & $\begin{array}{l}1696 \\
2857\end{array}$ \\
\hline Friuli-Venezia Giulia & $\begin{array}{l}2015 \\
2016\end{array}$ & $\begin{array}{l}2730 \\
5003\end{array}$ & $\begin{array}{l}4923 \\
5806\end{array}$ & $\begin{array}{l}1928 \\
3533\end{array}$ \\
\hline Marche & $\begin{array}{l}2015 \\
2016\end{array}$ & $\begin{array}{l}2907 \\
4533\end{array}$ & $\begin{array}{l}5231 \\
6169\end{array}$ & $\begin{array}{l}2913 \\
4543\end{array}$ \\
\hline Abruzzo & $\begin{array}{l}2015 \\
2016\end{array}$ & $\begin{array}{l}2064 \\
3714\end{array}$ & $\begin{array}{l}2769 \\
3266\end{array}$ & $\begin{array}{l}898 \\
1616\end{array}$ \\
\hline Molise & $\begin{array}{l}2015 \\
2016\end{array}$ & $\begin{array}{l}2020 \\
3353\end{array}$ & $\begin{array}{l}3385 \\
3992\end{array}$ & $\begin{array}{l}1602 \\
2659\end{array}$ \\
\hline Umbria & $\begin{array}{l}2015 \\
2016\end{array}$ & $\begin{array}{l}1828 \\
3162\end{array}$ & $\begin{array}{l}3077 \\
3629\end{array}$ & $\begin{array}{l}1327 \\
2295\end{array}$ \\
\hline Basilicata & $\begin{array}{l}2015 \\
2016\end{array}$ & $\begin{array}{l}1669 \\
2516\end{array}$ & $\begin{array}{l}1385 \\
1633\end{array}$ & $\begin{array}{l}521 \\
786\end{array}$ \\
\hline Trentino-Alto Adige & $\begin{array}{l}2015 \\
2016\end{array}$ & $\begin{array}{l}1413 \\
2789\end{array}$ & $\begin{array}{l}1692 \\
1996\end{array}$ & $\begin{array}{l}314 \\
620\end{array}$ \\
\hline Valle d'Aosta & $\begin{array}{l}2015 \\
2016\end{array}$ & $\begin{array}{l}209 \\
304\end{array}$ & $\begin{array}{l}3077 \\
3629\end{array}$ & $\begin{array}{l}2429 \\
3534\end{array}$ \\
\hline Tot. & $\begin{array}{l}2015 \\
2016\end{array}$ & $\begin{array}{l}104,750 \\
174,573\end{array}$ & $\begin{array}{l}153,842 \\
181,436\end{array}$ & $\begin{array}{l}66,972 \\
111,613\end{array}$ \\
\hline
\end{tabular}

${ }^{a}$ This category includes all immigrants who were relocated either to Centri di Prima Accoglienza or to SPRAR facilities

bThis category includes all immigrants who failed to obtain the status of refugee and were subsequently expelled, either from Centri di Prima Accoglienza or from SPRAR facilities. Immigrants who successfully managed to relocate to another country are also included in this category

Source: Italian Ministry of Interior, 2016 
the immigration policy implementation, a municipality periodically sets a predetermined number of immigrants to relocate to its hosting facilities ${ }^{5}$ after having reviewed the opinion of multiple subjects, above all firm representatives and local residents ${ }^{6}$; therefore, the subsequent chosen quota of immigrants to relocate to the city by the municipal authority also represents the result of a bargaining process between different (and often contrasting) opinions belonging to different actors. The resulting indisposition of the latter towards variations in the number of immigrants to be hosted (which was eventually obtained after the bargaining process) clearly represents a rigidity for the municipal authority when having to update its desired immigration policy. This can also explain why in municipalities where the level of these rigidities is high (i.e., high opposition towards variations in the acceptance rate of immigrants), when having to modify the desired quota of immigrants to host, in order to meet the discordant requests of firms and local residents, the rate of immigrant arrivals has to be updated periodically by the municipal authority; conversely, in those municipalities where the same actors involved do not appear to give particular importance to the immigration phenomenon, the margin of manoeuvre for implementing the desired immigration policy by the municipal authority is considerably higher, with resulting fewer and more stable changes in the rate of immigrant arrivals. Because of this, it was possible to assist to an heterogeneity in immigration policy behavior emerging among different municipalities (Corriere della Sera 2017).

The topic of immigration management in Europe (and Italy) is virtually absent in the literature, also due to the novelty of the recent and massive immigration flows towards the European Union. Relying on all the premises expressed above, the aim of this paper is to contribute to the literature by building a theoretical dynamic model addressing the recurrent issue of overcongestion afflicting the immigration hosting facilities of an increasing number of Italian municipalities. In this framework, a municipal authority faces a tradeoff between increasing the number of immigrants into its urban jurisdiction (which generates revenues) and optimal congestion level. Additionally, it is rational to assume that a municipal authority can utilize a share of the revenues to amplify the capacity of its hosting facilities, in this way decreasing the congestion level. As stressed, municipalities, in modifying the rate of change of immigration flows, must further take into account the level of rigidities exercised by both local residents and firms, who hence affect the process of policy implementation. Increasing the rate of immigrant arrivals might please firms and contribute to raise the municipal revenues, but at the same time, it can lead to situations of overcongestion and higher protests by local residents. Conversely, decreasing the same rate alleviates the issue of overcongestion and might please local residents but can be detrimental for firms and lead to a lower revenue receipt. From the model, two important findings emerge; firstly, at the steady-state level, the municipality always experiences a level of overcongestion (with respect to the optimal congestion level). Secondly, the different magnitude of the impact exercised by the level of rigidities can lead to different dynamic paths of convergence towards the steady state, namely monotonic or oscillatory. The rest of the paper is organized as follows. Section 2 introduces and solves the model. Section 3 concludes.

\section{Model}

Consider a single Italian municipal authority whose utility $U_{R}(\psi(t))$ at time $t$ is related to the revenues $R(t)(>0)^{7}$ provided by the central government for the flow of immigrants, 
$\psi(t)(\geq 0)$, which can be relocated to the city hosting facilities ${ }^{8}$. Specifically, the revenues of the municipal authority deriving from the accommodation of immigrants, $R(\psi)$ : $\mathbb{R}_{+} \mapsto \mathbb{R}$, increase in the number of immigrants entering its jurisdiction ${ }^{9}$.

$U_{R}(\psi(t))$ is assumed to satisfy the Inada conditions (i.e., being positive, strictly monotonically increasing, and concave, that is $U_{R}(\psi(t))>0, U_{R}^{\prime}{ }_{R}(\psi(t)) \equiv U_{R}^{\prime}(\cdot)>0$ and $U^{\prime \prime}{ }_{R}(\psi(t)) \equiv U^{\prime \prime}{ }_{R}(\cdot)<0$, with $\lim _{t \rightarrow+\infty} U_{R}^{\prime}(\psi(t))=0$ and $\left.\lim _{t \rightarrow 0} U^{\prime}{ }_{R}(\psi(t))=+\infty\right)$.

The hosting facilities have an optimal level of absorption, which coincides with the maximum stock of immigrants which can live in the facility, $\bar{\pi}(t)$. Nonetheless, assume that in order to reduce congestion, the authority can arbitrary utilize, at any time $t$, a share of the revenues to partially increase the optimal level of absorption of the facility, so that the latter is not static but can change over time.

Once they have been relocated to a municipality, immigrants are then subject to an additional check by the local security authorities and those who do not meet the requirements of asylum seekers are expelled. In light of these considerations, the relationship between the flow of immigrants entering and leaving the municipality and the dynamics of the congestion level of the hosting facilities at time $t, \pi(t)$, can be synthesized by the following differential equation:

$$
\pi \dot{(t)}=\psi(t)-\xi \pi(t)
$$

where $\xi(>0)$ represents the decongestion parameter denoting the rate at which immigrants are expelled from the municipality. Suppose then that deviations from the optimal congestion level provoked by the flow of immigrants are detrimental to the municipal authority according to the following functional form: $\Omega[\pi(t)-\bar{\pi}(t)]$; this disutility cost faced by the authority is assumed to be increasing and convex (i.e., $\Omega^{\prime}(\cdot) \equiv \frac{\partial \Omega[\cdot]}{\partial \pi(t)}>0$ and $\left.\Omega^{\prime \prime}(\cdot) \equiv \frac{\partial^{2} \Omega[\cdot]}{\partial \pi(t)^{2}}>0\right)$. In other words, this disutility cost of congestion will be considered by the municipal authority when setting the quotas of immigrants to be allowed in the city. With a total number of immigrants close to zero, the city will have no congestion in its hosting facilities, but the authority's utility will be null, since revenues from immigration will be zero. On the other hand, when the total number of immigrants increases, the municipal authority faces an additional trade-off between higher revenues together with higher congestion costs (if none or a reduced share of the revenues is utilized to decongestionate the hosting facilities) and a lower level of congestion at the expense of a lower net revenue receipt (when conversely a significant share of the revenues is utilized to decongestionate the hosting facilities).

The level of rigidities of external agents (namely, local residents and firms) in modifying the rate of allowed immigrants in the city (specific for each municipality) is captured by the constant parameter $\gamma(>0)^{10}$, which reflects a marginal, increasing, and convex disutility cost in the rate at which the change in the number of allowed immigrants takes place. In this setting, the (stock) variable of the number of allowed immigrants might constitute a sluggish control variable since, as mentioned above, the variable over which the municipal authority has a better and direct control is represented by the the rate of change in the flow of allowed immigrants; therefore, following the approach suggested by Feichtinger et al. (1994), I assume that the rate of change in the flow of allowed immigrants would constitute a better control variable rather than its stock.

Given all this, the maximization problem will consist of two state variables (the congestion level and the flow of immigrants relocated to the municipality) with their 
corresponding equation of motion and one control variable (the rate of change in the number of allowed immigrants). The utility of the municipal authority net of the the disutility costs of rigidities and congestion will be then:

$$
\hat{U}_{t}=U_{R}(\psi(t))-\gamma \frac{\dot{\psi(t)^{2}}}{2}-\Omega[\pi(t)-\bar{\pi}(t)]
$$

The squared term $\dot{\psi}(t)$ implies that the disutility of both increases and decreases in the rate of change of allowed immigrants is weighted in the same way ${ }^{11}$. Moreover, bigger variations in the rate of immigrant arrivals provoke a higher disutility with respect to smaller variations.

The intertemporal utility function for the municipal authority considered in an infinite time horizon can subsequently be expressed as follows:

$$
\int_{0}^{\infty} e^{-r t}\left\{U_{R}(\psi(t))-\gamma \frac{\dot{\psi(t})^{2}}{2}-\Omega[\pi(t)-\bar{\pi}(t)]\right\} d t
$$

with $r>0$ representing the exogenous discount rate.

Given a starting congestion level $\pi(0)=\pi_{0}$ and the dynamics of Eq. (1), a municipal authority has to choose the optimal path which maximizes its intertemporal utility function. In other words, the municipal authority's problem becomes that one of choosing the optimal rate of change in the number of immigrants allowed in the city given the dynamics of the equations of motion. To complete the dynamic framework, let us label the control variable measuring the rate of change in the flow of allowed immigrants, $\psi(t)$, as $v(t)$, so that $\dot{\psi}(t)=v(t)$. The intertemporal maximization problem can hence be written as:

$$
\begin{aligned}
\max _{\nu(t)} \int_{0}^{\infty} e^{-r t}\left\{U_{R}(\psi(t))-\gamma \frac{\nu(t)^{2}}{2}-\Omega[\pi(t)-\bar{\pi}(t)]\right\} d t \\
\text { s.t. } \quad \pi(t)=\psi(t)-\xi \pi(t), \quad \psi(t) \geq 0, \quad \pi(t)>0 \\
\psi \dot{\psi}(t)=v(t) \\
\pi(0)=\pi_{0} \\
\psi(0)=\psi_{0}
\end{aligned}
$$

From this, it is possible to derive the corresponding Hamiltonian function:

$$
\mathcal{H}(\psi, \pi, v, t)=U_{R}(\psi(t))-\gamma \frac{\nu(t)^{2}}{2}-\Omega[\pi(t)-\bar{\pi}(t)]+\lambda(t) v(t)+\tau(t)(\psi(t)-\xi \pi(t))
$$

where the two costate variables, $\lambda(t)$ and $\tau(t)$, represent, respectively, the shadow prices for the dynamics of the number of immigrants and the congestion level, denoting the marginal utility in relaxing the constraint (equivalently, the marginal disutility in tightening the constraint). Under the conditions guaranteeing the concavity of the Hamiltonian with respect to the control and state variables (see Appendix 1), the Mangasarian's theorem assures the existence of an interior optimum. 
From (5), the set of conditions for an optimal solution becomes:

$$
\begin{aligned}
& \partial_{\nu} \mathcal{H}(\psi, \pi, \nu, t)=-\gamma \nu(t)+\lambda(t) \\
& \dot{\psi(t)}=v(t) \\
& \pi(t)=\psi(t)-\xi \pi(t) \\
& \lambda \dot{(t)}=r \lambda(t)-\partial_{\psi} \mathcal{H}(\psi, \pi, v, t)=r \lambda(t)-\left[U_{R}^{\prime}(\cdot)+\tau(t)\right] \\
& \dot{\tau(t)}=r \tau(t)-\partial_{\pi} \mathcal{H}(\psi, \pi, \nu, t)=r \tau(t)-\left[-\Omega^{\prime}(\cdot)-\tau(t) \xi\right]
\end{aligned}
$$

with the limiting transversality conditions $\lim _{t \rightarrow+\infty} e^{r t} \tau(t) \pi(t)=0$ and $\lim _{t \rightarrow+\infty} e^{r t} \lambda(t) \psi(t)=0$ to assure a concave control problem. Equation (6) can also be rewritten as: $v(t)=\frac{\lambda(t)}{\gamma}$. From this, it can be observed how $v(t)$ is decreasing in $\gamma$; indeed, the higher is the level of rigidities, the lower will be the the rate of change in the allowance of immigrants, and this is to compensate the disutility cost of rigidities.

Subsequently, setting all the equations from (7) to (10) equal to 0 describes the solution to the achievement of the steady state ${ }^{12}$. First of all, from expression (7), it can be noticed that at the steady state, the rate of change of allowed immigrants in the city is null, that is $\nu^{*}=0$ (which also implies $\lambda^{*}=0$ ). Secondly, from expression (8), it is possible to obtain $\psi^{*}=\xi \pi^{*}$; therefore, the level of allowance of immigrants at the steady state depends on the congestion level at the steady state together with the rate of expulsion of immigrants. This also means that at the steady state, higher levels in the number of immigrants are associated with higher congestion levels, and at the same time, a higher level of expulsions corresponds to a higher number of immigrants relocated to the hosting facilities (and vice versa for lower levels of $\xi$ ). Finally, the level of $\tau(t)$ at the steady state from Eq. (10) results to be: $\tau^{*}=-\frac{\Omega^{\prime}\left(\pi^{*}-\bar{\pi}^{*}\right)}{\xi+r}$. Substituting then in expression (9), the values for $\lambda^{*}=0$ and $\tau^{*}$, I derive: $-U^{\prime} R\left(\psi^{*}\right)(\xi+r)+\Omega^{\prime}\left(\pi^{*}-\bar{\pi}^{*}\right)=0$, where $U_{R}^{\prime}{ }_{R}\left(\psi^{*}\right)$ and $\Omega^{\prime}\left(\pi^{*}-\bar{\pi}^{*}\right)$ are both positive; in order for the latter term to be positive to assure the equality, given that $\frac{\partial \Omega}{\partial\left(\pi^{*}\right)}=\Omega^{\prime}\left[\pi^{*}-\bar{\pi}^{*}\right]$, it must be that $\pi^{*}-\bar{\pi}^{*}>0$; therefore, the optimal solution at the steady-state level corresponds to a situation of overcongestion. This leads to the following proposition:

Proposition 1 Under the conditions provided by expressions (3) and (4) for the resolution of the intertemporal optimization problem, the corresponding steady-state level always leads to a situation of overcongestion in the number of immigrants accommodated in the hosting facilities.

This result shows that the optimal solution corresponds to a situation of overcongestion in the number of immigrants hosted by the municipal authority, and this is independent from the level of rigidities and the share of the revenues which the municipality decides to utilize for increasing the optimal level of absorption of the hosting facilities. Thus, at the steady-state level, rigidities play no role, and the change in the rate of allowed immigrants in the city is null. However, the same level of rigidities does affect the process of convergence towards the steady state; indeed, rearranging the terms in the expressions (7)-(10) and substituting (6) into (7) and (10), it is possible to get:

$$
\begin{aligned}
\psi \dot{\psi(}(t) & =\frac{\lambda(t)}{\gamma} \\
\dot{\pi(t)} & =\psi(t)-\xi \pi(t) \\
\lambda \dot{(}(t) & =r \lambda(t)-U^{\prime}{ }_{R}(\cdot)-\tau(t) \\
\tau \dot{(}(t) & =\tau(t)(r+\xi)+\Omega^{\prime}(\cdot)
\end{aligned}
$$


Subsequently, consider the Jacobian matrix at the steady-state level constituted by expressions (11)-(14):

$$
\begin{aligned}
\mathcal{J}\left(\psi^{*}, \pi^{*}, \lambda^{*}, \tau^{*}\right) & =\left[\begin{array}{llll}
\frac{\partial \psi(t)}{\partial \psi(t)} & \frac{\partial \psi(t)}{\partial \pi(t)} & \frac{\partial \psi(t)}{\partial \lambda(t)} & \frac{\partial \psi(t)}{\partial \tau(t)} \\
\frac{\partial \pi(t)}{\partial \psi(t)} & \frac{\partial \pi(t)}{\partial \pi(t)} & \frac{\partial \pi(t)}{\partial \lambda(t)} & \frac{\partial \pi(t)}{\partial \tau(t)} \\
\frac{\partial \lambda(t)}{\partial \psi(t)} & \frac{\partial \lambda(t)}{\partial \pi(t)} & \frac{\partial \lambda(t)}{\partial \lambda(t)} & \frac{\partial \lambda(t)}{\partial \tau(t)} \\
\frac{\partial \tau(t)}{\partial \psi(t)} & \frac{\partial \tau(t)}{\partial \pi(t)} & \frac{\partial \tau(t)}{\partial \lambda(t)} & \frac{\partial \tau(t)}{\partial \tau(t)}
\end{array}\right]= \\
& =\left[\begin{array}{cccc}
0 & 0 & \frac{1}{\gamma} & 0 \\
1 & -\xi & 0 & 0 \\
-U_{R}^{\prime \prime}(\cdot) & 0 & r & -1 \\
0 & \Omega^{\prime \prime}(\cdot) & 0 & r+\xi
\end{array}\right]
\end{aligned}
$$

The starting point to analyze the dynamics is to calculate the eigenvalues of the Jacobian at the steady state. Dockner (1985) proposes a formula to calculate the four eigenvalues $\left(E_{i}, i=1,2,3,4\right)$ of any Jacobian associated to the canonical equations deriving from the first-order conditions of a two-dimensional optimal control model (i.e., two state and one control variable):

$$
E_{i}=\frac{r}{2} \pm \sqrt{\left(\frac{r}{2}\right)^{2}-\frac{k}{2} \pm \frac{1}{2} \sqrt{k^{2}-4\|\mathcal{J}\|}}
$$

where $\|\mathcal{J}\|$ is the determinant of the Jacobian $\mathcal{J}$ and $k$ represents the sum of the determinants of the submatrices of $\mathcal{J}$ :

$$
k:=\left\|\begin{array}{ll}
\frac{\partial \dot{\psi}}{\partial \dot{\psi}} & \frac{\partial \dot{\psi}}{\partial \dot{\lambda}} \\
\frac{\partial \dot{\lambda}}{\partial \dot{\psi}} & \frac{\partial \dot{\lambda}}{\partial \dot{\lambda}}
\end{array}\right\|+\left\|\begin{array}{ll}
\frac{\partial \dot{\pi}}{\partial \dot{\pi}} & \frac{\partial \dot{\pi}}{\partial \dot{\tau}} \\
\frac{\partial \dot{\tau}}{\partial \dot{\tau}} & \frac{\partial \dot{\tau}}{\partial \dot{\tau}}
\end{array}\right\|+2\left\|\begin{array}{lll}
\frac{\partial \dot{\psi}}{\partial \dot{\tau}} & \frac{\partial \dot{\psi}}{\partial \dot{\tau}} \\
\frac{\partial \dot{\lambda}}{\partial \dot{\tau}} & \frac{\partial \dot{\lambda}}{\partial \dot{\tau}}
\end{array}\right\|
$$

From this, different equilibria in the path of convergence to the steady state can emerge, depending on the values of $\|\mathcal{J}\|$ and $k$.

The determinant of the Jacobian is:

$$
\|\mathcal{J}\|=\frac{1}{\gamma}\left[\Omega^{\prime \prime}(\cdot)-U_{R}^{\prime \prime}(\cdot) \xi(\xi+r)\right]
$$

which is always positive.

Then,

$$
k=\frac{U_{R}^{\prime \prime}(\cdot)}{\gamma}-\xi(\xi+r)
$$

is always negative.

These results suggest that the dynamics of convergence can either follow a monotonic path of convergence $\left(\right.$ if $k<0$ and $\left.0<\|\mathcal{J}\| \leq\left(\frac{k}{2}\right)^{2}\right)$ or an oscillatory path $\left(\text { if }\|\mathcal{J}\|>\left(\frac{k}{2}\right)^{2} \text { and }\|J\|>\left(\frac{k}{2}\right)^{2}+r^{2} \frac{k}{2}\right)^{13}$. Ultimately, monotonic convergence implies $\left(\frac{k}{2}\right)^{2} \geq\|\mathcal{J}\|$, whereas convergence through transient oscillations implies $\left(\frac{k}{2}\right)^{2}<\|\mathcal{J}\|$ (Feichtinger et al. 1994). Deriving

$$
\left(\frac{k}{2}\right)^{2}-\|\mathcal{J}\|=\frac{\gamma^{2}(\xi+r)^{2} \xi^{2}-\gamma\left(4 \Omega^{\prime \prime}(\cdot)-2 \xi(\xi+r) U^{\prime \prime}{ }_{R}(\cdot)\right)+U^{\prime \prime}{ }_{R}(\cdot)^{2}}{4 \gamma^{2}}
$$

it is easy to notice that the denominator of expression (18) is always positive. The numerator provides a quadratic form with respect to $\gamma$. To study the sign of the numerator, consider when the latter is equal or greater than zero, which is when $\gamma^{2}(\xi+r)^{2} \xi^{2}-$ 
$\gamma\left(4 \Omega^{\prime \prime}(\cdot)-2 \xi(\xi+r) U^{\prime \prime}{ }_{R}(\cdot)\right)+U^{\prime \prime}{ }_{R}(\cdot)^{2} \geq 0$; the roots of the corresponding equation solved for $\gamma$ are $\gamma_{1,2}=\Xi \pm \Theta$, with $\Xi=\frac{2 \Omega^{\prime \prime}(\cdot)-\xi(\xi+r) U^{\prime \prime} R_{R}(\cdot)}{\xi^{2}(\xi+r)^{2}}$ and $\Theta=2 \sqrt{\frac{\Omega^{\prime \prime}(\cdot)^{2}-\xi(\xi+r) \Omega^{\prime \prime}(\cdot) U^{\prime \prime} R_{R}(\cdot)}{\xi^{4}(\xi+r)^{4}}}$. Given that $\Theta>0$ and $\Xi>0$, with $|\Xi|>|\Theta|, \gamma_{1}$ and $\gamma_{2}$ are always distinct and positive. The set of solutions for the inequality is:

$$
\left\{\begin{array}{l}
\left(\frac{k}{2}\right)^{2}-\|\mathcal{J}\| \geq 0 \quad \Longleftrightarrow \quad \gamma \leq \Xi-\Theta \quad \text { or } \quad \gamma \geq \Xi+\Theta \\
\left(\frac{k}{2}\right)^{2}-\|\mathcal{J}\|<0 \quad \Longleftrightarrow \quad \Xi-\Theta<\gamma<\Xi+\Theta
\end{array}\right.
$$

In other words, if the level of rigidities expressed by the parameter $\gamma$ is lower or equal to $\gamma_{1}$ or higher or equal to $\gamma_{2}$, there will be monotonic convergence, whereas if the value of $\gamma$ lies between $\gamma_{1}$ and $\gamma_{2}$, there will be transient oscillations. This can be summarized in the following proposition:

Proposition 2 Under the conditions provided by expressions (3) and (4) for the resolution of the intertemporal optimization problem, there will be two different paths of convergence for the flow of immigrants and congestion level towards the steady state depending on the value assumed by $\gamma$. In particular, there will be monotonic convergence towards the steady state whenever $\gamma \in\left[0, \gamma_{1}\right] \cup\left[\gamma_{2}, \infty\right)$. Conversely, if $\gamma \in\left(\gamma_{1}, \gamma_{2}\right)$ the convergence process towards the steady state will acquire an oscillatory behavior.

Ultimately, the characterization of the dynamics towards the steady state will depend upon the level of rigidities, that hence help understanding the evolution of the current flows of immigrants who relocate to the Italian municipalities. For certain municipalities, where firms and local residents appear not to give particular importance to the immigration phenomenon, the level of rigidities towards variations in the rate of immigrant arrivals is reduced. As a consequence, these municipal authorities face a low level of pressure when setting or updating their desired immigration policy, so that the optimal number of immigrants who get relocated to the hosting facilities experiences a fast and monotonic increase in the process of convergence towards the steady state (for a graphical representation, see Appendix 2). Conversely, those municipalities facing higher levels of rigidities, in order to achieve the steady-state solution, are obliged to compromise continuously with firms and local residents, and the resulting bargaining process they have to go through provokes continuous alterations in the number of immigrants allowed to enter their jurisdiction. In other words, as the level of rigidities increases (i.e., both local residents and firms become more sensitive to variations in the rate of immigrant arrivals), the bargaining process that municipal authorities encounter gets stronger, and this lowers the margin of manoeuvre in adjusting their desired level of allowed immigrants, so that the rate of convergence slows down to compensate an increased disutility cost provoked by rigidities. Clearly, this leads to fluctuations in the process of convergence to the steady-state level of congestion as well as around it, until ultimately the steady-state level is reached. However, a different scenario could also emerge. Indeed, in the presence of a remarkably high level of rigidities, there will be a convergence towards the steady state following a dynamics similar to the former monotonic case. This happens because also the impact on the utility exercised by the levels of the number of immigrants and congestion increase with $\gamma$, and after a certain point, their 
level overcome the disutility cost of rigidities. That is to say, when the gap between optimal and current congestion levels of the immigration hosting facilities is too wide, the municipal authority needs to adjust rapidly the level of allowed immigrants in the city, in order to reduce the gap and eliminate a potential harmful risk due to an excessive level of under- or overcongestion; in this case, there will be a monotonic adjustment in the level of immigrants relocated to the hosting facilities. All these different scenarios can help explain the recent heterogeneity in immigration regulatory behavior emerging among different municipalities. It is also noteworthy to mention that the current heterogeneity of immigration policies among Italian municipalities did not lead to the emergence of a clear geographical cluster; indeed, within a same region (such as in Veneto or Lombardia, which in March 2016 were hosting, respectively, the 8 and 13\% of the total number of immigrants in Italy), some municipalities were prompted to modify their acceptance rate to accommodate relevant number of immigrants without significant external pressure, whereas other municipalities were subject to high levels of rigidities by different parties, so that the acceptance rate of immigrants witnessed alternative phases (Linkiesta 2017).

\section{Conclusion}

The massive immigration phenomenon which is affecting Europe nowadays represents a main issue on the agenda of European policymakers, especially in light of the financial costs associated to it and the fears and concerns raised among the citizens of the European Union. The repartition plan suggested by the European Commission to redistribute immigrants among member states currently encounters limited enforcement, primarily due to the strong opposition of many Eastern European countries which refuse to accept their quotas of immigrants. Nowadays, Italy is the European country which is receiving the highest number of daily arrivals of immigrants; the failure of the repartition plan, together with the reluctance of neighboring countries to accept immigrants, has obliged the Italian authorities to enact a national redistribution plan within the single municipalities. The latter are encouraged to welcome immigrants, thanks to the receipt of financial subsidies from the central government, and this has facilitated situations of overcongestions of the municipal immigration hosting facilities. The attitude towards immigration generally varies depending on the actors involved; while it is usually perceived as a negative phenomenon by the majority of local residents, conversely, it has been seen as an opportunity by most firms to face their increasing need for unskilled labor. Depending on the different degree of opposition/support to immigration by local residents and firms, different municipal authorities have been experiencing different margins of flexibility in implementing their desired immigration policy, particularly when having to modify their desired rate of immigrant arrivals; this can help to explain the emergence of heterogeneous behaviors in terms of immigration regulation among different municipalities. This paper has analyzed this emerging heterogeneity among municipalities and the subsequent dynamics of immigration flows towards the immigration hosting facilities. In an intertemporal dynamic framework, the municipal authority faces a trade-off between the level of allowed immigrants and congestion costs due to the limited hosting capacity of the hosting facilities. In this setting, the role exercised by rigidities capturing the degree of aversion of firms and local residents towards changes in the rate of allowed immigrants, appears to be crucial in explaining the dynamics of the immigration flows. Despite the 
fact that this model uses some simplifying assumptions, the emerging results are nonetheless important in shedding more light on the existing relationship between immigration flows, congestion of municipal hosting facilities, and rigidities exercised by firms and local residents in Italy. Particularly, from this analysis, two major findings emerge. Firstly, at the steady state, the optimal solution of congestion for the municipality always corresponds to a situation of overcongestion, and this is independent from the level of rigidities. However, the presence of rigidities that municipal authorities face when deciding the level of allowed immigrants determines the process of convergence towards the steady state, which can result in faster monotonic or slower oscillatory paths of convergence; both these two paths of convergence are the result of a rational outcome by the municipal authorities in facing rigidities when setting the desired share of immigrants to relocate to their hosting facilities.

\section{Endnotes}

${ }^{1}$ The vast majority of immigrants arriving in Italy holds a low level of education (Confindustria 2016).

${ }^{2}$ See Excelsior 2016.

${ }^{3}$ For a detailed report inherent the demand for immigrant workers by Italian firms disaggregated at sector level and according to type of contract in the year 2015, see Excelsior 2015.

${ }^{4}$ Following the adoption of the Pacchetto Immigrazione prepared by the Ministry of Interior in 2016, nowadays, immigrants hosted in municipal facilities waiting for the regularization of their residence permit (and, subsequently, for a hiring opportunity by firms) are employed by the municipality in socially useful works (in Italian, lavori socialmente utili $(L S U)$ ); the latter consist of activities of public interest regulated by the Italian law (e.g., street and park cleaning) and reserved to socially disadvantaged people.

${ }^{5}$ The frequency with which a municipal authority decides to maintain or update the number of immigrants to relocate to its hosting facilities varies depending on municipality, but generally, it is about a few weeks. Furthermore, for security reasons, each time the municipality also needs the formal approval of the corresponding Prefettura, the authority representing the Ministry of Interior at the local level.

${ }^{6}$ Every citizen has indeed the right to express his/her opinion on the immigration policy undertaken by the municipal authority.

${ }^{7}$ Assume $R$ as an undefined element of the utility function.

${ }^{8}$ In this model, for the sake of simplicity, I assume homogeneity of inflowing immigrants. Nonetheless, this assumption might constitute a limitation, since immigrants could differ from each other in terms of mentality, prospects to assimilate, and above all, education level. To cope with this issue, one way could be, for instance, to differentiate between skilled and unskilled immigrants. Ultimately, however, the features of the immigration flows involving Italy could partially mitigate the potential issue of heterogeneity among immigrants. Indeed, as reported in the descriptive statistics above, the great majority of immigrants arriving in Italy after the immigration emergency is from Sub-Saharan African countries; they hence share a common cultural background and usually hold a poor or no education level. Additionally, also immigrants arriving from other countries such as Pakistan or Bangladesh in most of the cases always possess a low level of education (Confindustria 2016). 
${ }^{9}$ Another limitation of this model relies on the fact that important aspects such as the impact exercised by immigrants on the labor market and the role of both fiscal and market size effects of immigration are neglected. A more extensive analysis incorporating such issues could indeed provide a better and more sophisticated framework. Nonetheless, the contribution of immigrants to the total demand for low-skilled labor, although being important, remains reduced if compared to the overall low-skilled workforce employed by firms. Additionally, as expressed above, some bureaucratic barriers still lengthen the hiring process of immigrants by firms, in this way also contributing to increase the congestion level of municipal hosting facilities. As for the fiscal effects of immigration, despite the fact that some studies detected a positive impact of immigration on the welfare system of Western countries (see, e.g., Dustman and Frattini (2014)), other studies suggest that the same result could differ substantially depending upon the methodology employed, and thus the same final impact might be also considered minimal (Chojnicki 2013). The Italian case analyzed by this model depicts a reality in which the immigrants residing in the hosting facilities generally do not participate to the fiscal contribution (at least in the short run). The issue of market size effects of immigration raises a more complicated scenario, also due to the fact that the latter have been understudied in the literature; however, some of the most recent studies have highlighted how immigrants can positively affect the aggregate demand for goods (see, e.g., Aubry et al. 2016; Di Giovanni et al. 2014). In this model, for the sake of simplicity, the market size effects of immigration are neglected.

${ }^{10}$ For the sake of simplicity, I assume that local residents and firms share the same level of rigidities; this means that in each municipality, their degree of sensitivity with respect to (opposite) variations in the rate of immigrant arrivals is the same.

${ }^{11}$ For the sake of simplicity, I assume that the (opposite) level of rigidities of firms and local residents are equally counterbalanced.

${ }^{12}$ The values at the steady-state level are indicated by the superscript asterisk (*).

${ }^{13}$ The latter condition for oscillatory convergence, $\|\mathcal{J}\|>\left(\frac{k}{2}\right)^{2}+r^{2} \frac{k}{2}$, is always verified, since $k<0$.

\section{Appendix 1}

\section{Necessary and sufficient conditions for the concavity of the Hamiltonian}

The gradient of the value function is:

$$
\nabla f_{\psi, \pi, \nu}=\left[U_{R^{\prime}}(\cdot),-\Omega^{\prime}(\cdot),-\gamma v(t)\right]
$$

From which the associated Hessian matrix is derived:

$$
\hat{H}(f)=\left[\begin{array}{ccc}
U_{R}{ }^{\prime \prime}(\cdot) & 0 & 0 \\
0 & -\Omega^{\prime \prime}(\cdot) & 0 \\
0 & 0 & -\gamma
\end{array}\right]
$$

The concavity of the Hamiltonian requires the three principal minors of the Hessian matrix $\left(A_{1,1}, A_{2,2}\right.$ and $A_{3,3}$, respectively) to be $A_{1,1}<0, A_{2,2}>0$ and $A_{3,3}<0$.

$$
\begin{aligned}
& A_{1,1}=U_{R}{ }^{\prime \prime}(\cdot)(<0) \text {, since } U^{\prime \prime}(\cdot)<0 \\
& A_{2,2}=-U_{R}{ }^{\prime \prime}(\cdot) \Omega^{\prime \prime}(\cdot)(>0), \text { since } \Omega^{\prime \prime}(\cdot)>0 \\
& A_{3,3}=U_{R}{ }^{\prime \prime}(\cdot) \Omega^{\prime \prime}(\cdot) \gamma(<0), \text { since } \gamma>0 \quad \square
\end{aligned}
$$




\section{Appendix 2}

Phase diagram for the dynamics of converge towards the steady state with no rigidities $(\gamma=0)$

Due to the presence of four eigenvalues associated to the Jacobian matrix deriving from expressions (11)-(14), the complete graphical characterization of the dynamics of convergence towards the steady state is not possible, since this would entail a four-dimensional phase diagram. However, the monotonic case of convergence when $\gamma=0$ (i.e., when the level of rigidities encountered by a municipality is null) can be represented through a phase diagram, as this would reduce the Jacobian to a $2 \times 2$ matrix. Particularly, when $\gamma=0$, the intertemporal utility function for the municipal authority becomes:

$$
\int_{0}^{\infty} e^{-r t}\left\{U_{R}(\psi(t))-\Omega[\pi(t)-\bar{\pi}(t)]\right\} d t
$$

In this setting, the optimal control problem reduces to one state variable $(\pi(t))$ and one control variable $(\psi(t))$, always subject to expression (1), with the municipal authority considering the starting congestion level $\pi(0)=\pi_{0}$; however, in this case the municipality can chose any level of immigration flow, since the absence of rigidities no longer decreases its utility level. The resulting Hamiltonian function associated to this framework writes as:

$$
\overline{\mathcal{H}}=U_{R}(\psi(t))-\Omega[\pi(t)-\bar{\pi}(t)]+\tau(t)(\psi(t)-\xi \pi(t))
$$

Given the fact that the condition of concavity remains satisfied for the Hamiltonian in expression (21), the resulting set of necessary and sufficient conditions becomes ${ }^{14}$ :

$$
\begin{aligned}
\partial_{\psi} \overline{\mathcal{H}} & =0 \Leftrightarrow U^{\prime}{ }_{R}(\cdot)+\tau=0 \\
\dot{\pi} & =\psi-\xi \pi \\
\dot{\tau} & =r \tau-\partial_{\pi} \overline{\mathcal{H}}=r \tau-\left[-\Omega^{\prime}(\cdot)-\tau \xi\right]
\end{aligned}
$$

with the required transversality condition: $\lim _{t \rightarrow+\infty} e^{r t} \tau(t) \pi(t)=0$.

The steady state for $\psi^{*}$ and $\pi^{*}$ associated to the system of Eqs. (22)-(24) meets the following conditions:

$$
\begin{aligned}
\psi^{*} & =\xi \pi^{*} \\
U_{R}^{\prime}(\cdot)(r+\xi) & =\Omega^{\prime}(\cdot)(>0)
\end{aligned}
$$

Therefore, the steady state for $\gamma=0$ always corresponds to a situation of overcongestion.

In order to provide a graphic representation of the dynamics towards the steady state, it becomes necessary to derive the trajectories of congestion and immigration flows. From Eq. (23), the isocline $\dot{\pi}=0$ is represented by the locus of points by which $\psi=\xi \pi$, and the resulting slope of the isocline is given by the value of the parameter $\xi$. To derive the locus of points and the slope of the second isocline, start by rewriting expression (22) as:

$$
\tau=-U_{R}^{\prime}(\cdot)
$$


Then, differentiate expression (22) with respect to $t$, substitute the corresponding costate variable, $\dot{\tau}$, with the right-hand side of Eq. (24) and plug in $\tau$ the right-hand side of Eq. (27) to obtain:

$$
\frac{U_{R}^{\prime}(\cdot)}{U^{\prime \prime}{ }_{R}(\cdot)} \dot{\psi}=-\frac{\Omega^{\prime}(\cdot)}{U^{\prime}{ }_{R}(\cdot)}+(r+\xi)
$$

Now, assume that the instantaneous utility from the arrival of immigrants by the municipal authority is given by:

$$
U_{R}(\psi)=\psi^{\phi}
$$

where $\phi(0<\phi<1)$ represents the utility elasticity. Then, in order to obtain the isocline $\dot{\psi}=0$, plug the right-hand side of Eq. (29) in expression (28) to get:

$$
\dot{\psi}=\frac{(r+\xi) \psi}{(\phi-1)}-\frac{\Omega^{\prime}(\cdot)}{\phi(\phi-1) \psi^{\phi-2}}
$$

Subsequently, setting expression (30) equal to zero, solving for $\psi$, and differentiating provides the slope of the isocline:

$$
\left.\frac{d \psi}{d \pi}\right|_{\dot{\psi}=0}=\frac{1}{\phi-1}\left[\frac{\Omega^{\prime}(\cdot)}{(r+\xi) \phi}\right]^{\frac{\phi}{1-\phi}} \Omega^{\prime \prime}(\cdot)
$$

recalling that $\Omega(\cdot) \equiv \Omega[\pi-\bar{\pi}], \Omega^{\prime}(\cdot) \equiv \frac{\partial \Omega[\cdot]}{\partial \pi}>0$, and $\Omega^{\prime \prime}(\cdot) \equiv \frac{\partial^{2} \Omega[\cdot]}{\partial \pi^{2}}>0$, the slope of the isocline $\dot{\psi}=0$ is always negative.

Next, consider the Jacobian matrix $J=\left(\begin{array}{ll}a 11 & a 12 \\ a 21 & a 22\end{array}\right)$ associated to expressions (23) and (30), whose elements are defined as:

$$
\begin{aligned}
& a 11=\frac{\partial_{\dot{\pi}}}{\partial_{\pi}}=-\xi \\
& a 12=\frac{\partial_{\dot{\pi}}}{\partial_{\psi}}=1 \\
& a 21=\frac{\partial_{\dot{\psi}}}{\partial_{\pi}}=-\frac{\Omega^{\prime \prime}(\cdot)}{\phi(\phi-1) \psi^{\phi-2}} \\
& a 22=\frac{\partial_{\dot{\psi}}}{\partial_{\psi}}=\frac{r+\xi}{(1-\phi)}-\frac{(2-\phi) \psi^{1-\phi} \Omega^{\prime}(\cdot)}{\phi(\phi-1)}
\end{aligned}
$$

Substituting in $a 22$ the steady-state condition (26), the former expression becomes:

$$
a 22=\frac{\partial_{\dot{\psi}}}{\partial_{\psi}}=\frac{r+\xi}{(1-\phi)}-\frac{(2-\phi)(r+\xi)}{\phi-1}
$$

For a $2 \times 2$ Jacobian matrix, the corresponding eigenvalues are provided by the following formula:

$$
e_{1,2}=\frac{1}{2}\left[\operatorname{tr}(J) \pm \sqrt{\left(\operatorname{tr}(J)^{2}-4\|J\|\right.}\right]
$$

where $\operatorname{tr}(J)$ and $\|J\|$ represent, respectively, the trace and the determinant of $J$. Given that $\operatorname{tr}(J)>0$ and $\|J\|<0$, expression (32) provides two real eigenvalues of opposite sign, which entails that the steady state is a saddle point which can be reached along monotonic optimal paths of immigration flows and congestion.

With the aim of deriving the directions of change in immigration flows, differentiate expression (30) with respect to $\pi$; since $\frac{\dot{\psi}}{\pi}>0$, at any point above(/below) the $\dot{\psi}=0$ locus, $\psi$ increases(/decreases) in the vertical direction. In a similar fashion, from Eq. (23), 


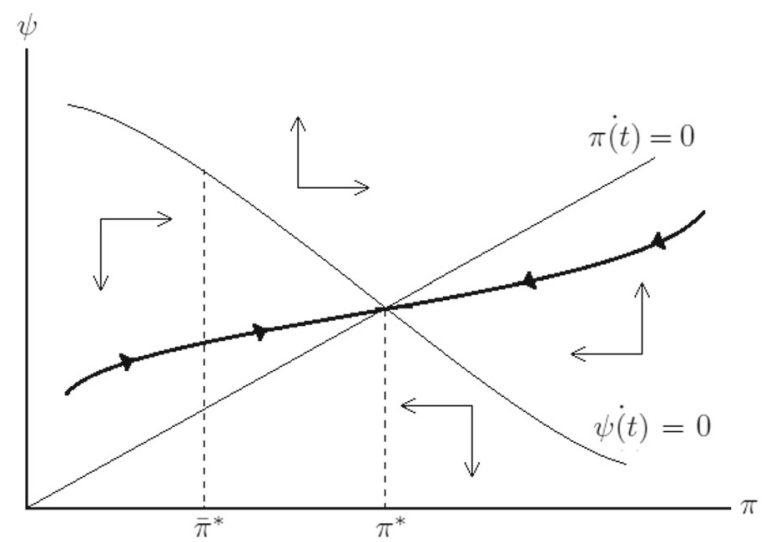

Fig. 1 Phase diagram for the dynamics of convergence towards the steady state (monotonic case)

since $\frac{\dot{\pi}}{\psi}>0$, at any point to the left(/right) of the $\dot{\pi}=0$ locus, $\pi$ increases (/decreases) in the horizontal direction.

Figure 1 provides the phase diagram for the dynamics of convergence towards the steady state, with the level of rigidities being null (i.e., $\gamma=0$ ). The intersection point of the two isoclines denotes the steady-state level of overcongestion, with the bold line representing the optimal monotonic trajectories of immigration flows and congestion.

\section{Acknowledgements}

The author would like to thank the anonymous referee and the editor for the useful remarks. Responsible editor: David Lam

\section{Competing interests}

The IZA Journal of Development and Migration is committed to the IZA Guiding Principles of Research Integrity. The author declares that he has observed these principles.

\section{Publisher's Note}

Springer Nature remains neutral with regard to jurisdictional claims in published maps and institutional affiliations.

Received: 7 March 2017 Accepted: 23 May 2017

Published online: 28 December 2017

\section{References}

Aubry A, et al. The welfare impact of global migration in OECD countries. In: Journal of International Economics 101; 2016. p. $1-21$.

BBC. 2016. Technical report. http://www.bbc.com/news/world-europe-35974982. Accessed 6 Apr 2016.

Chojnicki X. The fiscal impact of immigration in france: a generational accounting approach. World Econ. 2013;36(8): 1065-90.

Confindustria. Immigrati: Da emergenza a opportunita'. dimensione, effetti economici e politiche. 2016. Technical report, (in Italian). http://www.interno.gov.it/sites/default/files/allegati/segiugno2016_parte_speciale_immigrazione.pdf.

della Sera C. 2017. Technical report, (in Italian). http://www.corriere.it/cronache/17_gennaio_06/migranti-roma-premio4-milioni-5ab6e1ba-d38c-11e6-9dc7-b8de3918521a.shtml?refresh_ce-cp. Accessed 5 Jan 2017.

Di Giovanni J, et al. A global view of cross-border migration. J Eur Econ Assoc. 2014;13(1):168-202.

Dockner E. Local stability analysis in optimal control problems with two state variables. 1985. Optimal control theory and economic analysis 2 (North-Holland, Amsterdam), 89-103.

Dustmann C, Frattini T. The fiscal effects of immigration to the UK. Econ J. 2014;124:593-643.

Eumetra. 2016. Technical report, (in Italian). https://www.eumetramr.com/it/lopinione-degli-italiani-sullarrivo-degliimmigrati. Accessed 15 Jan 2016.

Excelsior. 2015. Technical report, (in Italian). http://excelsior.unioncamere.net/images/pubblicazioni2015/ excelsior_2015_immigrati.pdf. Accessed Nov 2015.

Excelsior. 2016. Technical report, (in Italian). http://excelsior.unioncamere.net/images/pubblicazioni2016/ excelsior_2016_immigrati.pdf. Accessed Nov 2016.

Daily Express. 2016. Technical report. http://www.express.co.uk/news/world/644405/czech-republic-slovakia-hungarypoland-fence-migrants-out-europe. Accessed 15 Feb 2016.

Finotelli C, Arango J. Regularisation of unauthorised immigrants in Italy and Spain: determinants and effects. Documents d'Analisi Geografica. 2011;57(3):495-515. 
Feichtinger G, Noval A, Wirl F. Limit cycles in intertemporal adjustment models: theory and applications. J Econ Dynam Control. 1994;18(2):353-80

Giornale I. 2014. Technical report, (in Italian). http://www.ilgiornale.it/news/cronache/accogliere-immigrati-eccoquanto-si-guadagna-1049569.html. Accessed 6 Sept 2014.

Giornale I. 2016a. Technical report, (in Italian). http://www.ilgiornale.it/news/politica/abbattere-muri-anti-migranti-renzilascia-alfano-tira-dritto-1340377.html. Accessed 8 Dec 2016.

Giornale, I. 2016b. Technical report, (in Italian). http://www.lgiornale.it/news/politica/renzi-e-business-degli-immigratiai-comuni-500-euro-migrante-1323141.html. Accessed 25 Oct 2016.

II Messaggero. 2016. Technical report, (in Italian). http://www.Imessaggero.it/primopiano/cronaca/ migranti_centri_accoglienza_caos-2024725.html. Accessed 14 Oct 2016.

Istat. Statistical Report. 2016. http://stra-dati.istat.it/Index.aspx.

La Repubblica. 2016. Technical report, (in Italian). http://ricerca.repubblica.it/repubblica/archivio/repubblica/2016/11/20/ e-al-collasso-la-rete-dellaccoglienzaMilano01.html. Accessed 20 Nov 2016.

Linkiesta. 2017. Technical report, (in Italian). http://www.linkiesta.it/it/article/2017/01/05/ecco-i-comuni-chedovrebbero-accogliere-i-migranti-e-non-lo-fanno/32868/. Accessed 5 Jan 2017.

Ministry of Interior. Statistical report. 2016. http://www.libertaciviliimmigrazione.dlci.interno.gov.it/it/documentazione/ statistica.

The Daily Telegraph. 2015. Technical report. http://www.telegraph.co.uk/news/worldnews/europe/italy/11542063/ italians-revolt-against-migrant-invasion.html. Accessed 16 Apr 2015.

TGcom24. 2016. Technical report, (in Italian). http://www.tgcom24.mediaset.it/cronaca/migranti-il-piano-di-minnitiaprire-un-cie-in-ogni-regione-e-raddoppiare-espulsioni_3048882-201602a.shtml. Accessed 31 Dec 2016.

TGcom24. 2017. Technical report, (in Italian). http://www.tgcom24.mediaset.it/cronaca/migranti-l-italia-delle-protestela-mappa-interattiva_3038454-201702a.shtml. Accessed 4 Jan 2017.

The New York Times. 2016. Technical report. https:/www.nytimes.com/2016/04/15/world/europe/after-europe-andturkey-strike-a-deal-fears-grow-that-migrants-will-turn-to-italy.html. Accessed 14 Apr 2016.

UNHCR. Population statistics. 2016. https://data2.unhcr.org/en/situations/mediterranean/location/5205.

\section{Submit your manuscript to a SpringerOpen ${ }^{\circ}$ journal and benefit from:}

- Convenient online submission

- Rigorous peer review

- Open access: articles freely available online

- High visibility within the field

- Retaining the copyright to your article

Submit your next manuscript at $\boldsymbol{\triangleright}$ springeropen.com 